\section{Effect of Sorbitol on the Urinary Excretion of some B Vitamins in Man}

THE inclusion of sorbitol in the diets of rats makes them able to survive and grow in the absence of dietary sources of $\mathrm{B}$ vitamins ${ }^{1}$. It is likely that the sorbitol acts by increasing the synthesis of these vitamins in the alimentary canal. We have investigated the possibility that sorbitol similarly increases synthesis in man. We have done this by determining the urinary output of three vitamins in a male subject aged 27 (J.D.W.) before, during and after the ingestion of sorbitol.

Urine was collected for exactly twelve hours daily, for four days a week, over a period of 26 weeks. From the beginning of the fifth week to the end of the thirteenth week sorbitol was taken. The intention was to begin with $20 \mathrm{gm}$. daily for two or three days, and to increase it within two weeks to $50 \mathrm{gm}$. daily. However, occasional mild diarrhoea led to reduction of the dose from time to time, so that the daily intake varied between 20 and $40 \mathrm{gm}$. during the nine weeks of supplementation. The vitamins investigated were thiamine, riboflavin and nicotinic acid. We measured the excretion of the first two as such, and of the major excretory product of the third, $\mathbf{N}^{1}$-methylnicotinamide. Fluorometric methods were used for all estimations; that of Mawson and Thompson for thiamine ${ }^{2}$, of Slater and Morell for riboflavin $^{3}$ and of Carpenter and Kodicek for $\mathrm{N}^{1}$-methylnicotinamide ${ }^{4}$.

The subject kept a weighed record of all the food he ate during the 26 weeks of experiment; the nutrients therein were calculated from food tables. There was little variation in the intake of any nutrients, including the three vitamins under study; in particular, there was no significant difference in intake between the periods before, during and after the consumption of the sorbitol (Table 1).

The excretion of the vitamins fluctuated con. siderably (Fig. 1). The ingestion of sorbitol produced no effect during the first week or more, but then there was a distinct increase of excretion of all three vitamins. When the sorbitol was stopped, there was again no change for a week or more. After this, the excretion of thiamine and riboflavin fell, but the excretion of $\mathrm{N}^{1}$-methylnicotinamide remained at the level it had reached with sorbitol. It is possible that

Table 1. Average Dally Intake of Calories and Nutrients.

\begin{tabular}{|c|c|c|c|}
\hline & $\begin{array}{l}\text { Weeks 1-4 } \\
\text { (before } \\
\text { sorbitol) }\end{array}$ & $\begin{array}{l}\text { Weeks 5-13 } \\
\text { (during } \\
\text { sorbitol) }\end{array}$ & $\begin{array}{c}\text { Weeks 14-26 } \\
\text { (after } \\
\text { sorbitol) }\end{array}$ \\
\hline Calories $\quad \ldots, \ldots$ & 2420 & 2290 & 2270 \\
\hline Carbohydrate $(\mathrm{gm}.) \ldots$ & 290 & 285 & 285 \\
\hline Fat (gm.) , .. & 103 & 97 & 94 \\
\hline Thiamine (mgm.) & $1 \cdot 1$ & $\mathbf{1} \cdot 1$ & $1 \cdot 05$ \\
\hline Riboflavin (mgm.) ... & $2 \cdot 1$ & $2 \cdot 0$ & $2 \cdot 0$ \\
\hline Nicotinic acid (mgm.) & $14 \cdot 1$ & $13 \cdot 6$ & $13 \cdot 7$ \\
\hline
\end{tabular}

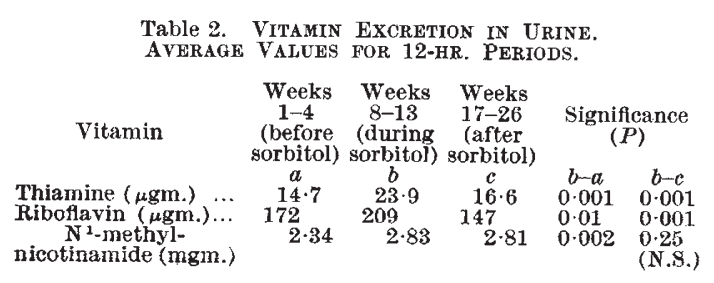

Sorbitol, 20-40 $\mathrm{gm}$. daily, was taken during 5 th to 13 th weeks of the experiment. Urine was collected for $12 \mathrm{hr}$. each day from Monday to Thursday.

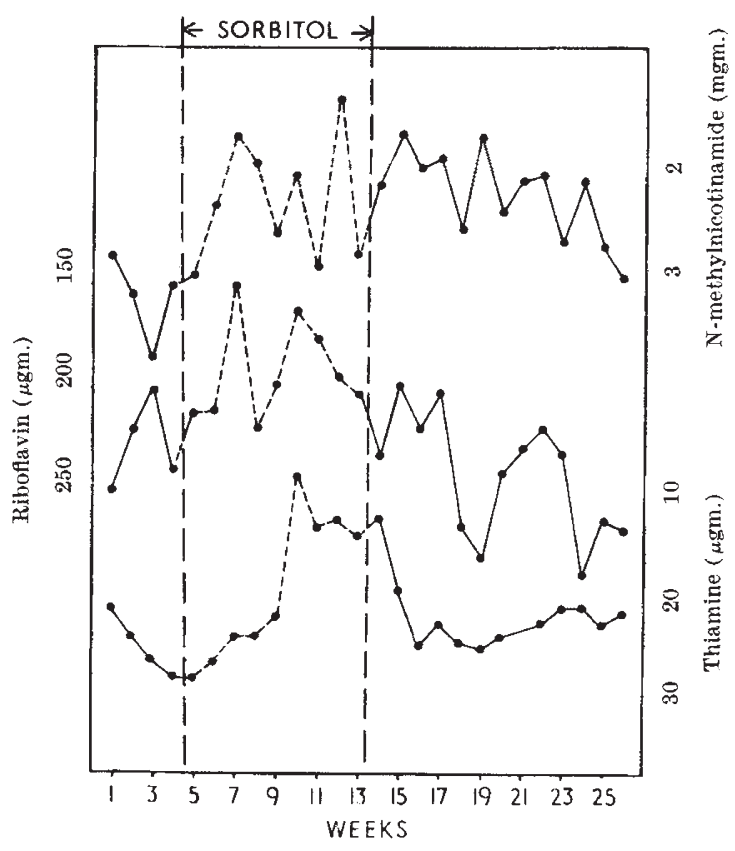

Fig. 1. Effect of sorbitol on urinary excretion of $\mathbf{B}$ vitamins. of $20-40$ excretion of $B$ vitamins before, during and after ingestion excretions for 4 days weekly.

this might also have shown a fall if we had continued with the study for a longer period. For statistical calculation, it seemed reasonable to omit a transition period of three weeks following the beginning or end of sorbitol administration (Table 2). We then find that the increases in excretion of all three vitamins with sorbitol, and the decreases in excretion of thiamine and riboflavin after sorbitol, are significant at levels of 1 per cent or less.

The effect of sorbitol on increasing the excretion of vitamins might be due either to increased synthesis with subsequent absorption, or to enhanced absorption of the vitamins already present in the diet. The latter mechanism, it has been suggested, occurs with vitamin $\mathrm{B}_{12}$ (ref. 5). However, we already know from our animal experiments that sorbitol induces a synthesis of B vitamins. It is also known that vitamins synthesized in the human gut may be absorbed. We are inclined therefore to believe that our results are due to increased synthesis of three of the vitamins which are then absorbed. The delay in the effect of sorbitol on the excretion of these vitamins would support the suggestion that the effect is on microbial synthesis rather than on absorption. The final decision, however, must. depend on further investigation.

$$
\begin{gathered}
\text { J. D. WATSON } \\
\text { JoHN YUDKIN } \\
\text { Department of Nutrition, Queen Elizabeth College } \\
\text { (University of London), Campden Hill Road, } \\
\text { London, W.8. } \\
\text { July 30. }
\end{gathered}
$$

\footnotetext{
1 Morgan, T. B., and Yudkin, J., Nature, 180, 543 (1957). ${ }^{2}$ Mawson, E. H., and Thompson, S. Y., Biochem. J., 43, 2 (1948) 3 Slater, E. C., and Morell, D. B., Biochem. J., 40, 644 (1946). ${ }_{5}^{4}$ Carpenter, K. J., and Kodicek, E., Biochem. J., 46, 421 (1950) Gulesnick. M., Herndon, J. F., Rice, E. G., Parmelee, E. T.,
} 